\title{
Study of Age and Gender Related Variations in Position of Mental Foramen of Some Egyptians Using Digital Panoramic Radiography
}

\author{
Afaf Abd El-Raouf Shaaban ${ }^{1}$ and Ossama Sayed Ahmed El-Shall ${ }^{2}$
}

1 Forensic Medicine and Clinical Toxicology, Faculty of Medicine for Girls, Al-Azhar University.

2 Oral Medicine, Periodontology, Radiology \& Diagnosis Department, Faculty of Dental Medicine, Al-Azhar University, Girls Branch

\begin{abstract}
Introduction: The mandible is the strongest bone in the human body and persists in a wellpreserved state longer than any other bone. One of mandibular characteristic that can prove very helpful for age and gender determination is mental foramen. Aim: The aim of this study was to determine the radiographic position of mental foramen in relation to anatomical structures in different age groups in some male and female Egyptians. Subjects and Methods: The study group comprised a total of 200 patients; 100 males (aging from 8.7 to 66.0 years old) and 100 females (aging from 8.4 to 66.5 years old), attending the outpatient clinics of the Faculty of Dental Medicine for girls, Al Azhar University, in Cairo, and required panoramic radiography for various dental treatments. The study population was divided into five age groups; 8-12 years, 13-17 years, 18-30 years, 31-50 years, and 51-70 years. On panoramic radiographs, the following parameters were measured; MF-ML: distance from mental foramen to the midline, MF-ABC: distance from mental foramen to the alveolar bone crest, MF-BM: distance from mental foramen to the base of mandible. These measurements were compared between different age groups and both sexes. Results: The results indicated that the mean values of the distance between mental foramen and the midline (MF$\mathrm{ML})$, the alveolar bone crest (MF-ABC) and the base of mandible (MF-BM) increase in a significant accelerating manner in children, become stable after the age of 18 and after the age of 50 the mental foramen becomes closer to the alveolar crest. As regards sex difference, males showed higher mean values than females in all measurements in all age groups except in the age group (8-12) years. Conclusion: This study concluded that the position of mental foramen varies with age, and there is a gender related variation in its position. Using mental foramen position measurements may be helpful to predict age and sex on panoramic radiographs for Egyptians. Recommendation: Further research and studies are needed with extensive and large number of samples from different districts of Egypt, in order to accurate assessment of position of mental foramen in Egyptians that would help in establishing its role in forensic applications.
\end{abstract}

\footnotetext{
Introduction

A nalyzing the morphological characteristics of bone is a common approach used by anthropologists and forensic dentists in individual identification (Thakur et al., 2014).

The contribution of dentistry in human identification takes two main forms: the identification of human remains according to dental records existing ante-mortem, and a postmortem dental profiling in cases where there are no ante-mortem records (Rashid and Ali, 2011).

Many anatomical landmarks like frontal bone, orbital bone, maxillary sinus, tooth and jaws in human skull can be used in forensic science for individual identification or for determination of sex or age of the person (Matamala et al., 2009).

In cases of mass disasters where skull fragments are found, personal identification with $100 \%$ accuracy is not possible and it depends largely on the available parts of skeleton. In such type of cases, parts
}

of skull as mandible are of the prime importance for the identification of an unknown person (Sweet, 2001).

The mandible is the strongest bone in the human body and persists in a well-preserved state longer than any other bone. Therefore, the use of morphological features of the mandible is a common approach used by anthropologists and forensic dentists in the determination of age and gender (Hu et al., 2006).

One of mandibular characteristic that can prove very helpful for age and gender determination is mental foramen (Durić et al., 2005). It is paired; present lateral to the mental protuberance (chin) on the body of mandible, usually inferior to the apices of the mandibular first and second premolars on either side (Haghanifar and Rokouei, 2009).

The mental foramen is a funnel like opening which is transmitting mental nerves and vessels which supplies sensory innervations to lower lip, buccal 
vestibule and gingival mesial to first mandibular molar (Shah et al., 2013).

Usually, the mental foramen is difficult to locate. There are no absolute anatomical landmarks for reference and the foramen cannot be clinically visualized or palpated (Bou Serhal et al., 2002).

Prior to surgery, knowledge of the exact location ensures effective mental block anesthesia. One of the inadvertent complications that occur during implant placement in anterior mandible is a neurosensory alteration in the chin and lower lip due to improper identification and protection of the mental foramen and anterior mental loop (Shah et al., 2010).

The mental foramen morphology, in terms of position, varies not only according to age, sex and ethnicity but even within the same race, in different geographic regions and within the inhabitants of the same geographic area (Pokhrel and Bhatnagar, 2013).

Several studies comparing different radiographic methods to assess the location of the mental foramen have suggested that digital panoramic radiographs show least error in the imaging of the mental foramen (Peker et al., 2009). On radiograph the mental foramen presents as a single circular or elliptical radiolucent area bilaterally in the premolar region (Neves et al., 2010).

The panoramic radiography (OPG) provides the ability to view the entire body of the mandible and allows a more accurate location of the mental foramen in both horizontal as well as in vertical dimensions (Sahni et al., 2015). It is considered the most preferred diagnostic modality as it allows a more accurate localization of mental foramen (Malik et al., 2016).

The radiographs are indispensable tools that are used in forensic anthropology. The radiographic method is simplest and cheapest method for age estimation and gender determination when compared to the histological and biocthemical methods (Chandra et al., 2013). Among radiographic methods is panoramic radiography which is a widely used technique because it has the advantage of providing, in a single film, the image of the full mandible with relatively less exposure, time, and cost (Rockenbach et al., 2003).

The availability of panoramic imaging in the dental office and its widely use for evaluation of the jaws, justify the interest in determining the visibility of anatomical structures on these films (Jacobs et al., 2004).

Panoramic digital radiography can be applied in forensic medicine with the utilization of portable units. This approach is less time-consuming and allows the extra-oral examination of the dental status (Rashid and Ali, 2011).

Skeletal characteristics visible on panoramic radiographs provide enough information when anteand postmortem films are compared (Komar and Lathrop, 2006). These skeletal characteristics vary by population; therefore, there is a need for populationspecific standards (Mohamed et al., 2016).

\section{Aim of the work}

The purpose of this work is to study the change in position of mental foramen of some Egyptians in different age groups and to determine gender related variations using digital panoramic radiography.

\section{Subjects and Methods}

The study group comprised a total of 200 patients (100 males and 100 females) attending the outpatient clinics of the Faculty of Dental Medicine for girls, Al Azhar University, Cairo, Egypt during the period from January 2016 to December 2016, and required panoramic radiography for various dental treatments.

The study population was divided into five age groups; 8-12 years, 13-17 years, 18-30 years, 31-50 years, and 51-70 years.

Chronologic age of an individual was calculated by subtracting the birth date from the date on which the radiographs were exposed for that particular individual. Decimal age was taken for simplicity of statistical calculation and ages were estimated on yearly basis e. g. 12 years 9 months as 12.75 years and it was considered in 12 years age group. All male and female subjects involved in the study were Egyptian in origin.

\section{Ethical considerations:}

- Approval was obtained from chairman of Oral Medicine, Periodontology, Radiology \& Diagnosis Department, Faculty of Dental Medicine, Al-Azhar University, Girls Branch.

- Prior to any procedure, the studied cases (or their families) were informed about the nature, and benefits of participation in the study. An informed written consent was obtained from them denoting convince and agreement about the research program of the experiment design.

- Confidentiality of cases records was maintained.

\section{Inclusion criteria:}

All cases included in this study have fulfilled the following criteria: 1- No history of any systemic disease that might affect bone metabolism, 2-any pathology or congenital anomaly in the mandible that could affect the interpretation of radiographic image were excluded, 3- No abnormal dental condition, e.g. impaction, transposition and congenitally missing teeth, 4- No history of trauma or disease to the head, face \& neck, 5- No history of orthodontic or maxillofacial surgery, 6- high quality radiographs with clearly seen mental foramen and border of mandible.

\section{Exclusion criteria:}

1- Non- Egyptian origin, 2- Congenital anomalies, 3Aplasia or other abnormal dental conditions, 4- History of prolonged illness, trauma or disease to the head, face \& neck, orthodontic or maxillofacial surgery, 5Distortion of images, presence of artifacts or no visualization of mental foramen.

\section{The Equipment Used:}

I. Orthopantomogram machine (PM 2002 EC Proline).

II. Films: - Kodak 6x12.

III. Scanner: vista 4000 U X-ray. The radiographic images were digitized using the scanner.

IV. Computer: the images were recorded in a computer file. Radiographic images were then processed using computer-aided program AutoCAD 2000. 


\section{The Procedures Used:}

Orthopantomogram (OPG):

The subject was asked to remove any piercing, hair accessories, jewelry, dentures, hair grips, eyeglasses and metal objects from the head and neck that could interfere with the $\mathrm{x}$-ray images. Lead gowns were put to protect the rest of the body.

OPG were taken with the patient in the standing position, with placing his chin on a chin rest and bite on a plastic piece with a disposable cover to hold the jaws in place so that all the teeth, especially the crowns, can be viewed individually. It is very important that to follow all instructions and hold absolutely still once positioned while the arm of the OPG machine rotates slowly around the head.

\section{Mental Foramen Position Parameters:}

On orthopantomogram, position of mental foramen $(\mathrm{X})$ was fixed in relation to three reference lines (Figure 1)

- Alveolar bone crest (ABC),

- Base of mandible (BM),

- The midline (ML) (a line is drawn from the anterior nasal spine to the most inferior portion of mentis).

On both sides of the mandible the following parameters were measured in millimeters according to Mohamed et al. (2016) (Figure 1):

- MF-ML: distance from mental foramen to the midline,

- MF-ABC: distance from mental foramen to the alveolar bone crest,

- MF-BM: distance from mental foramen to the base of mandible.

There is no statistical difference between the positions of the mental foramen on either side of a patient (Wang et al., 1986; Oguz and Bozkir, 2002; Junior et al., 2009; Rashid and Ali, 2011; Malik et al., 2016); therefore, the distances from any side can be used. So the mean was taken as a single measurement per sample.

\section{Statistical Analysis:}

Recorded data were analyzed using the statistical package for social sciences, version 20.0 (SPSS Inc., Chicago, Illinois, USA) (Bourke et al., 1985). Quantitative data were expressed as mean \pm standard deviation (SD). Qualitative data were expressed as frequency and percentage. The following tests were done:

- Chi- square $\left(\mathrm{x}^{2}\right)$ test: The test was used to study the association between different categorical variables and to compare between categorical data.

- Linear regression was used to obtain regression formulae using chronological age as the dependent variable. Other measurements were the independent variables.

- Standard error of the estimate (SE) was also calculated, it predicts the deviation of estimated age from the actual chronological age.

- Student t-test of significance was used when comparing between two means. A one-way analysis of variance (ANOVA) when comparing between more than two means.
- Pearson's correlation coefficient (r) test was used for correlating data.

- Confidence interval test was used to obtain range for gender determination using measurements as independent variables.

- The significance level was set at $\mathrm{P} \leq 0.05$.

\section{Results:}

The study population included 200 persons; 100 males (aging from 8.7 to 66.0 years old) and 100 females (aging from 8.4 to 66.5 years old). Age and gender distribution of subjects are illustrated in (Table 1). There was non-statistical significant difference between age groups in both male and female cases.

Comparison of mental foramen position measurements between age groups in female subjects is illustrated in (Table 3- Figure 3). Females aged (8-12) years showed the statistically significant lowest mean values, followed by females aged (13-17) years. There was no statistically significant difference between females aged (18-30), (31-50) and (51-70) years; all showed the statistically significant highest mean values.

Comparison of mental foramen position measurements between age groups in male subjects is illustrated in (Table 2- Figure 2). Males aged (8-12) years showed the statistically significant lowest mean values, followed by males aged (13-17) years. There was no statistically significant difference between males aged (18-30), (31-50) and (51-70) years; all showed the statistically significant highest mean values.

Comparison of mental foramen- midline (MFML) measurement between male and female cases is illustrated in (Table 4- Figure 4). In the age groups (1317, 18-30, 31-50 and 51-70), males showed higher mean values than females. While in the age group (812), females showed higher mean values than males.

Comparison of mental foramen- alveolar bone crest (MF-ABC) measurement between male and female cases is illustrated in (Table 5- Figure 5). In the age groups (13-17, 18-30, 31-50 and 51-70), males showed higher mean values than females. While in the age group (8-12), females showed higher mean values than males.

Comparison of mental foramen- base of mandible (MF-BM) measurement between male and female cases is illustrated in (Table 6- Figure 6). In the age groups (13-17, 18-30, 31-50 and 51-70), males showed higher mean values than females. While in the age group (8-12), females showed higher mean values than males.

The correlation between chronological age and mental foramen position measurements in male cases in different age groups is illustrated in (Table 7- Figures 7, $8,9,10,11,12)$. In the age groups (8-12 and 13-17), there was a statistical significant positive correlation between chronological age and all measurements. While in the age groups (18-30, 31-50 and 51-70), there was no significant correlation between the age and the studied measurements.

The correlation between chronological age and mental foramen position measurements in female cases in different age groups is illustrated in (Table 8- Figures $13,14,15,16,17,18)$. In the age groups (8-12 and 13- 
17), there was a statistical significant positive correlation between chronological age and all measurements. While in the age groups (18-30, 31-50 and 51-70), there was no significant correlation between the age and the studied measurements.

In the age groups (8-12 and 13-17), there was a statistical significant positive correlation between chronological age and the mental foramen position measurements, so regression analysis was developed in order to determine the equations for age estimation using these measurements (Table 9).

The confidence interval test was used to obtain range for gender determination using the mental foramen position measurements (Table 10).

Table (1): Chi- square test for age and gender distribution of cases:

\begin{tabular}{|c|c|c|c|c|c|c|c|c|}
\hline \multirow{2}{*}{$\begin{array}{c}\text { Age groups } \\
\text { (years) }\end{array}$} & \multicolumn{2}{|c|}{ Males } & \multicolumn{2}{c|}{ Females } & \multicolumn{2}{c|}{ Total } & \multicolumn{2}{c|}{ Chi-square } \\
\cline { 2 - 7 } & No. & $\%$ & No. & $\%$ & No. & \% & $\mathbf{x}^{2}$ & $\boldsymbol{p}$ \\
\hline $8-12$ & 14 & $14.0 \%$ & 15 & $15.0 \%$ & 29 & $14.5 \%$ & & \\
\hline $13-17$ & 23 & $23.0 \%$ & 22 & $22.0 \%$ & 45 & $22.5 \%$ & & \\
\hline $18-30$ & 22 & $22.0 \%$ & 29 & $29.0 \%$ & 51 & $25.5 \%$ & \multirow{3}{*}{0.870} & 0.786 \\
\hline $31-50$ & 18 & $18.0 \%$ & 14 & $14.0 \%$ & 32 & $16.0 \%$ & & \\
\hline $51-70$ & 23 & $23.0 \%$ & 20 & $20.0 \%$ & 43 & $21.5 \%$ & & \\
\hline Total & 100 & $100.0 \%$ & 100 & $100.0 \%$ & 200 & $100.0 \%$ & & \\
\hline
\end{tabular}

*: Significant at $P \leq 0.05$

Table (2): ANOVA one way statistical analysis of mental foramen position measurements between age groups in male subjects:

\begin{tabular}{|c|c|c|c|c|}
\hline \multirow{2}{*}{\multicolumn{2}{|c|}{ Age groups (years) }} & \multicolumn{3}{|c|}{ Measurements (mm) } \\
\hline & & MF-ML & MF-ABC & MF-BM \\
\hline \multicolumn{2}{|c|}{$8-12$} & $26.31 \pm 0.34$ & $11.56 \pm 1.04$ & $7.52 \pm 0.49$ \\
\hline \multicolumn{2}{|c|}{$13-17$} & $28.56 \pm 1.33$ & $14.99 \pm 1.36$ & $11.73 \pm 1.83$ \\
\hline \multicolumn{2}{|c|}{$18-30$} & $32.31 \pm 1.13$ & $17.91 \pm 1.23$ & $14.93 \pm 0.55$ \\
\hline \multicolumn{2}{|c|}{$31-50$} & $34.33 \pm 1.15$ & $17.95 \pm 1.40$ & $14.13 \pm 0.83$ \\
\hline \multicolumn{2}{|c|}{$51-70$} & $33.02 \pm 1.25$ & $15.26 \pm 1.00$ & $14.74 \pm 0.68$ \\
\hline \multirow{3}{*}{ ANOVA } & $\mathrm{F}$ & 147.823 & 76.125 & 143.116 \\
\hline & LSD & 4.01 & 3.20 & 3.71 \\
\hline & $p$ & $<0.001^{*}$ & $<0.001^{*}$ & $<0.001 *$ \\
\hline
\end{tabular}

*: Significant at $P \leq 0.05$, LSD: Least Significant Difference.

Table (3): ANOVA one way statistical analysis of mental foramen position measurements between age groups in female subjects:

\begin{tabular}{|c|c|c|c|c|}
\hline \multirow{2}{*}{ Age groups (years) } & \multicolumn{3}{|c|}{ Measurements (mm) } \\
\cline { 2 - 5 } & MF-ML & MF-ABC & MF-BM \\
\hline $8-12$ & $26.79 \pm 0.46$ & $13.25 \pm 1.05$ & $8.16 \pm 0.76$ \\
\hline $13-17$ & $28.21 \pm 0.52$ & $14.05 \pm 1.04$ & $11.30 \pm 1.24$ \\
\hline $18-30$ & $31.88 \pm 1.45$ & $16.83 \pm 1.27$ & $13.41 \pm 1.17$ \\
\hline \multicolumn{2}{|c|}{$31-50$} & $33.36 \pm 0.63$ & $16.88 \pm 0.94$ & $12.85 \pm 0.86$ \\
\hline \multicolumn{2}{|c|}{$51-70$} & $31.14 \pm 0.73$ & $13.22 \pm 1.20$ & $13.61 \pm 1.03$ \\
\hline \multirow{3}{*}{ ANOVA } & $\mathrm{F}$ & 143.17 & 53.63 & 76.60 \\
\cline { 2 - 5 } & LSD & 3.29 & 1.83 & 2.73 \\
\cline { 2 - 5 } & $p$ & $<0.001 *$ & $<0.001^{*}$ & $<0.001^{*}$ \\
\hline
\end{tabular}

*: Significant at $P \leq 0.05$, LSD: Least Significant Difference.

Table (4): Student t-test, comparison of mental foramen- reference line (MF-ML) measurement between male and female cases:

\begin{tabular}{|c|c|c|c|c|c|}
\hline \multirow{2}{*}{$\begin{array}{l}\text { Age groups } \\
\text { (years) }\end{array}$} & \multicolumn{5}{|c|}{ MF-ML (mm) } \\
\hline & Males & Females & Difference & SE & $P$-value \\
\hline $8-12$ & $26.31 \pm 0.34$ & $26.79 \pm 0.46$ & -0.48 & 0.151 & $0.004^{*}$ \\
\hline $13-17$ & $28.56 \pm 1.33$ & $28.21 \pm 0.52$ & 0.35 & 0.305 & 0.257 \\
\hline $18-30$ & $32.31 \pm 1.13$ & $31.88 \pm 1.45$ & 0.43 & 0.373 & 0.259 \\
\hline $31-50$ & $34.33 \pm 1.15$ & $33.36 \pm 0.63$ & 0.98 & 0.341 & $0.008^{*}$ \\
\hline $51-70$ & $33.02 \pm 1.25$ & $31.14 \pm 0.73$ & 1.88 & 0.319 & $<0.001 *$ \\
\hline
\end{tabular}

SE $=$ standard error, *: Significant at $P \leq 0.05$ 
Table (5): Student t-test, comparison of mental foramen- alveolar bone crest (MF-ABC) measurement between male and female cases:

\begin{tabular}{|c|c|c|c|c|c|}
\hline \multirow{2}{*}{$\begin{array}{c}\text { Age groups } \\
\text { (years) }\end{array}$} & Males & Females & Difference & SE & $P$-value \\
\cline { 2 - 6 } & $11.56 \pm 1.04$ & $13.25 \pm 1.05$ & -1.69 & 0.389 & $<0.001^{*}$ \\
\hline $13-17$ & $14.99 \pm 1.36$ & $14.05 \pm 1.04$ & 0.94 & 0.361 & $0.013^{*}$ \\
\hline $18-30$ & $17.91 \pm 1.23$ & $16.83 \pm 1.27$ & 1.07 & 0.355 & $0.004^{*}$ \\
\hline $31-50$ & $17.95 \pm 1.40$ & $16.88 \pm 0.94$ & 1.07 & 0.435 & $0.020^{*}$ \\
\hline $51-70$ & $15.26 \pm 1.00$ & $13.22 \pm 1.20$ & 2.04 & 0.335 & $<0.001^{*}$ \\
\hline
\end{tabular}

$S E=$ standard error, *: Significant at $P \leq 0.05$

Table (6): Student t-test, comparison of mental foramen- base of mandible (MF-BM) measurement between male and female cases:

\begin{tabular}{|c|c|c|c|c|c|}
\hline \multirow{2}{*}{$\begin{array}{c}\text { Age groups } \\
\text { (years) }\end{array}$} & \multicolumn{5}{|c|}{ MF-BM (mm) } \\
\hline & Males & Females & Difference & SE & $P$-value \\
\hline $8-12$ & $7.52 \pm 0.49$ & $8.16 \pm 0.76$ & -0.64 & 0.241 & $0.014^{*}$ \\
\hline $13-17$ & $11.73 \pm 1.83$ & $11.30 \pm 1.24$ & 0.43 & 0.468 & 0.363 \\
\hline $18-30$ & $14.93 \pm 0.55$ & $13.41 \pm 1.17$ & 1.52 & 0.269 & $<0.001 *$ \\
\hline $31-50$ & $14.13 \pm 0.83$ & $12.85 \pm 0.86$ & 1.28 & 0.300 & $<0.001 *$ \\
\hline $51-70$ & $14.74 \pm 0.68$ & $13.61 \pm 1.03$ & 1.13 & 0.263 & $<0.001^{*}$ \\
\hline
\end{tabular}

SE $=$ standard error, *: Significant at $P \leq 0.05$

Table (7): Pearson's correlation coefficient for the correlation between chronological age and mental foramen position measurements in male cases in different age groups:

\begin{tabular}{|c|c|c|c|c|c|c|}
\hline \multirow{3}{*}{$\begin{array}{l}\text { Age groups } \\
\text { (years) }\end{array}$} & \multicolumn{6}{|c|}{ Measurements (mm) } \\
\hline & \multicolumn{2}{|c|}{ MF-ML } & \multicolumn{2}{|c|}{ MF-ABC } & \multicolumn{2}{|c|}{ MF-BM } \\
\hline & $\begin{array}{l}\text { Correlation } \\
\text { coefficient (r) }\end{array}$ & P-value & $\begin{array}{l}\text { Correlation } \\
\text { coefficient (r) }\end{array}$ & P-value & $\begin{array}{l}\text { Correlation } \\
\text { coefficient (r) }\end{array}$ & P-value \\
\hline $8-12$ & 0.858 & $<0.001 * *$ & 0.856 & $<0.001 * *$ & 0.891 & $<0.001 * *$ \\
\hline 13-17 & 0.942 & $<0.001 * *$ & 0.873 & $<0.001 * *$ & 0.918 & $<0.001 * *$ \\
\hline 18-30 & 0.442 & 0.281 & 0.773 & 0.245 & 0.418 & 0.152 \\
\hline 31-50 & 0.303 & 0.171 & 0.207 & 0.355 & 0.308 & 0.163 \\
\hline $51-70$ & -0.164 & 0.516 & 0.434 & 0.072 & 0.471 & 0.149 \\
\hline
\end{tabular}

**: Highly Significant at $P \leq 0.001$

Table (8): Pearson's correlation coefficient for the correlation between chronological age and mental foramen position measurements in female cases in different age groups:

\begin{tabular}{|c|c|c|c|c|c|c|}
\hline \multirow{2}{*}{$\begin{array}{c}\text { Age groups } \\
\text { (years) }\end{array}$} & \multicolumn{2}{|c|}{ MF-RL } & \multicolumn{2}{c|}{ MF-ABC } & \multicolumn{2}{c|}{ MF-BM } \\
\cline { 2 - 7 } & $\begin{array}{c}\text { Correlation } \\
\text { coefficient (r) }\end{array}$ & P-value & $\begin{array}{c}\text { Correlation } \\
\text { coefficient (r) }\end{array}$ & P-value & $\begin{array}{c}\text { Correlation } \\
\text { coefficient (r) }\end{array}$ & P-value \\
\hline $8-12$ & 0.912 & $<0.001^{* *}$ & 0.969 & $<0.001 * *$ & 0.927 & $<0.001^{* *}$ \\
\hline $13-17$ & 0.760 & $<0.001^{* *}$ & 0.363 & $<0.001 * *$ & 0.843 & $<0.001^{* *}$ \\
\hline $18-30$ & -0.235 & 0.221 & -0.134 & 0.488 & -0.286 & 0.133 \\
\hline $31-50$ & 0.938 & 0.086 & -0.309 & 0.283 & 0.278 & 0.336 \\
\hline $51-70$ & 0.252 & 0.284 & 0.450 & 0.096 & -0.025 & 0.917 \\
\hline
\end{tabular}

**: Highly Significant at $P \leq 0.001$

Table (9): Regression equations for age estimation using mental foramen position measurements in the age groups (8-12 and 13-17):

\begin{tabular}{|c|c|}
\hline & Regression equation \\
\hline Males & Age $=(0.456 \mathrm{MF}-\mathrm{ML})+(0.430 \mathrm{MF}-\mathrm{ABC})+(0.285 \mathrm{MF}-\mathrm{BM})-8.463$ \\
\hline Females & Age $=(0.1 .438 \mathrm{MF}-\mathrm{ML})+(-0.026 \mathrm{MF}-\mathrm{ABC})+(0.860 \mathrm{MF}-\mathrm{BM})-35.350$ \\
\hline
\end{tabular}

Table (10): Confidence interval test for gender determination using mental foramen position measurements:

\begin{tabular}{|c|c|c|c|c|c|c|}
\hline \multirow{4}{*}{ Measurements } & \multicolumn{6}{|c|}{ Confidence interval range $(\mathrm{mm})$} \\
\hline & \multicolumn{3}{|c|}{ Males } & \multicolumn{3}{|c|}{ Females } \\
\hline & \multirow{2}{*}{ Mean } & \multicolumn{2}{|c|}{ C.I. 95\% } & \multirow{2}{*}{ Mean } & \multicolumn{2}{|c|}{ C.I. 95\% } \\
\hline & & \multicolumn{2}{|c|}{ LowerUpper } & & \multicolumn{2}{|c|}{ LowerUpper } \\
\hline MF-ML & 31.13 & 30.54 & 31.73 & 30.37 & 29.89 & 30.85 \\
\hline MF-ABC & 15.75 & 15.26 & 16.23 & 14.97 & 14.57 & 15.37 \\
\hline MF-BM & 12.97 & 12.43 & 13.51 & 12.12 & 11.69 & 12.55 \\
\hline
\end{tabular}




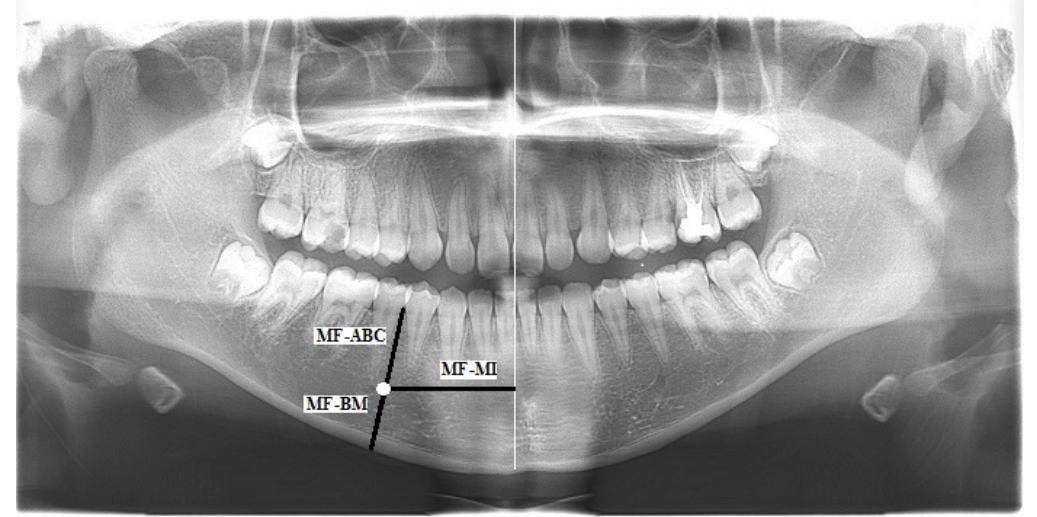

Fig, (1): Panoramic radiograph, MF-ML: distance from mental foramen to the midline, MF-ABC: distance from mental foramen to the alveolar bone crest, MF-BM: distance from mental foramen to the base of mandible

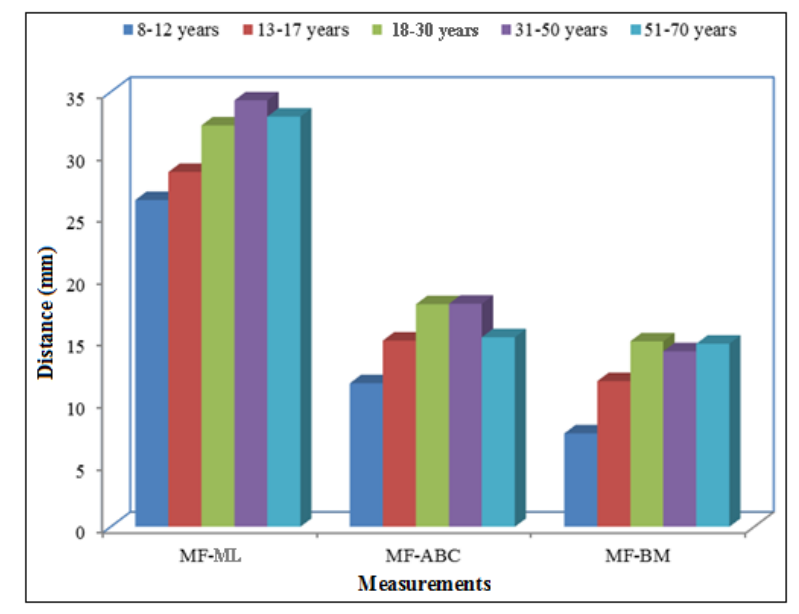

Figure (2): Comparison of mental foramen position measurements in male subjects.

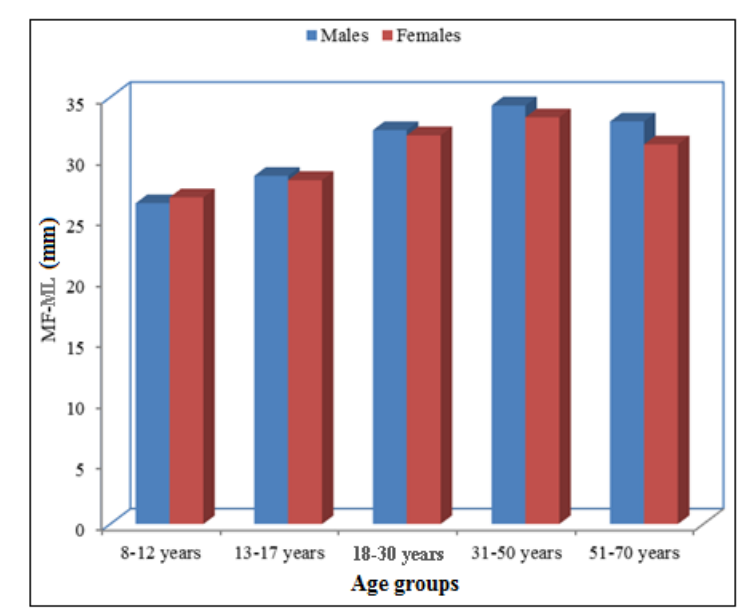

Figure (4): Comparison of mental foramen- reference line (MF-ML) measurement between male and female cases.

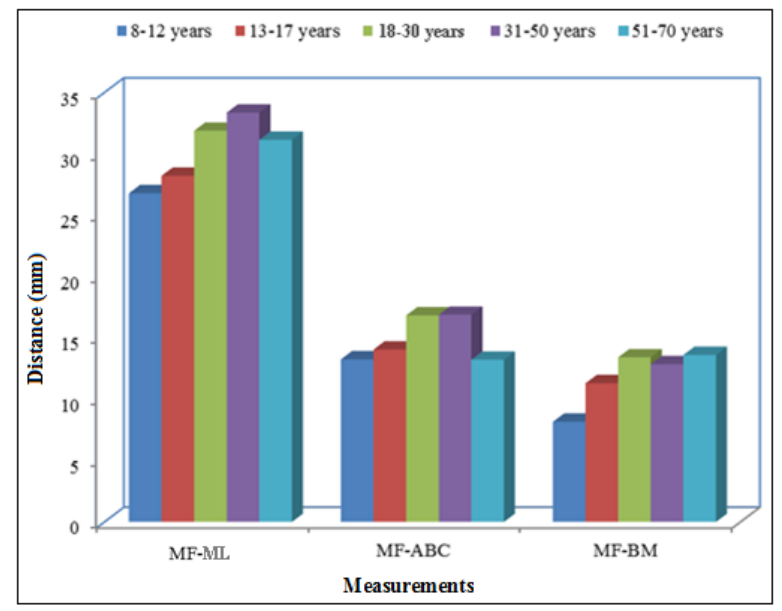

Figure (3): Comparison of mental foramen position measurements in female subjects.

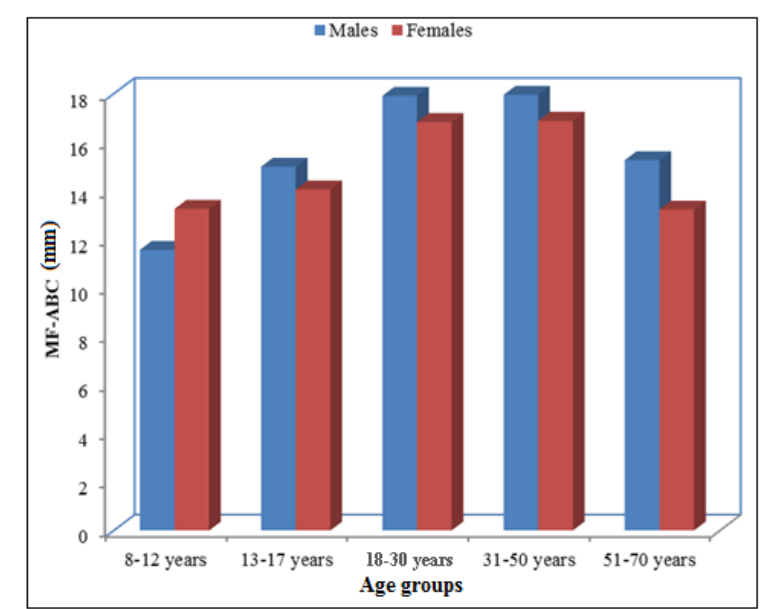

Figure (5): Comparison of mental foramen- alveolar bone crest (MF-ABC) measurement between male and female cases. 


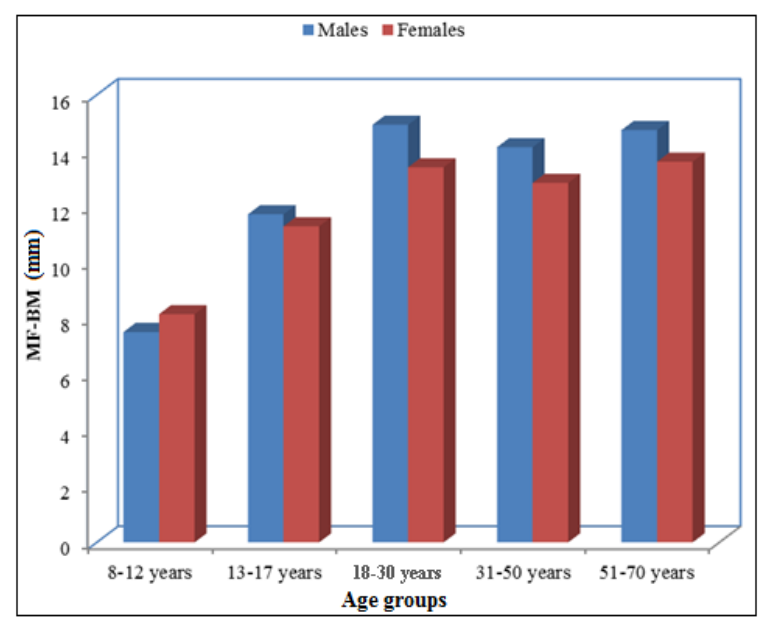

Figure (6): Comparison mental foramen- base of mandible (MF-BM) measurement between male and female cases.

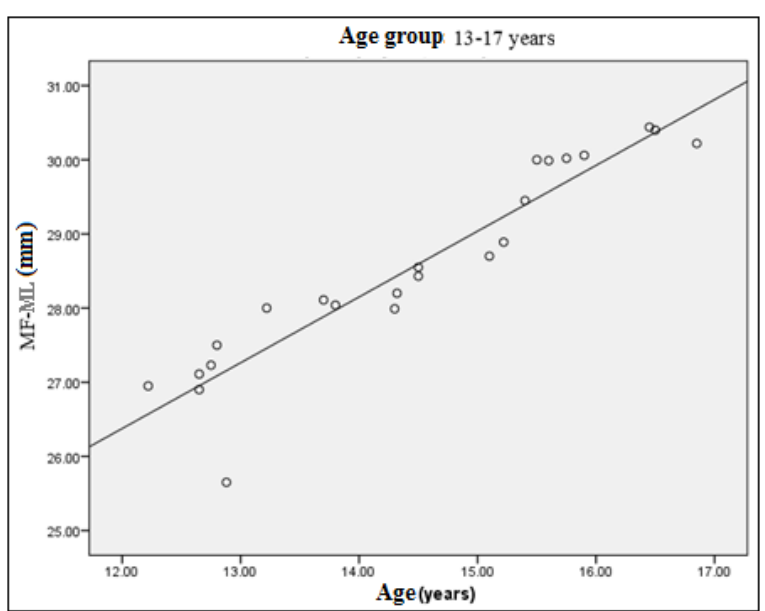

Figure (8): Scatter diagram showing correlation between chronological age and mental foramenmidline (MF-ML) measurement in in the age group (13-17) of male cases.

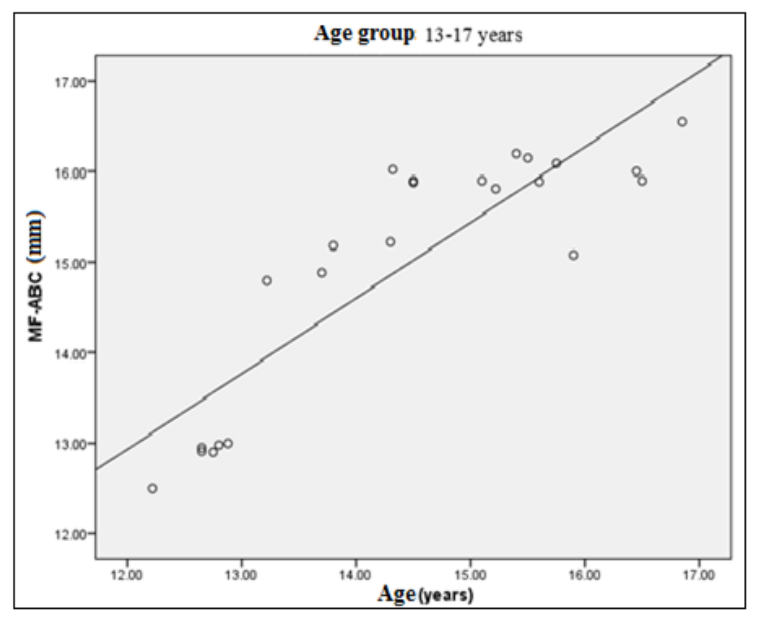

Figure (10): Scatter diagram showing correlation between chronological age and mental foramenmidline (MF-ABC) measurement in in the age group (13-17) of male cases.

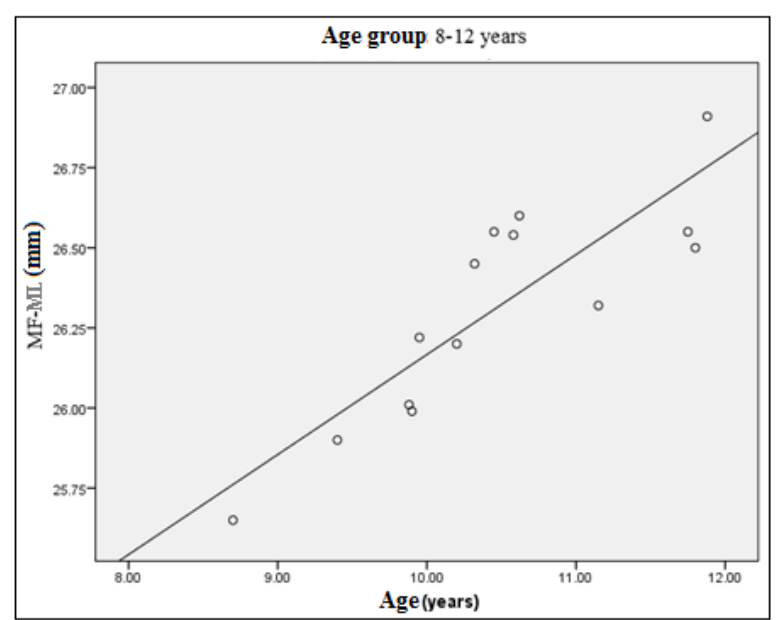

Figure (7): Scatter diagram showing correlation between chronological age and mental foramenmidline (MF-ML) measurement in in the age group (812) of male cases.

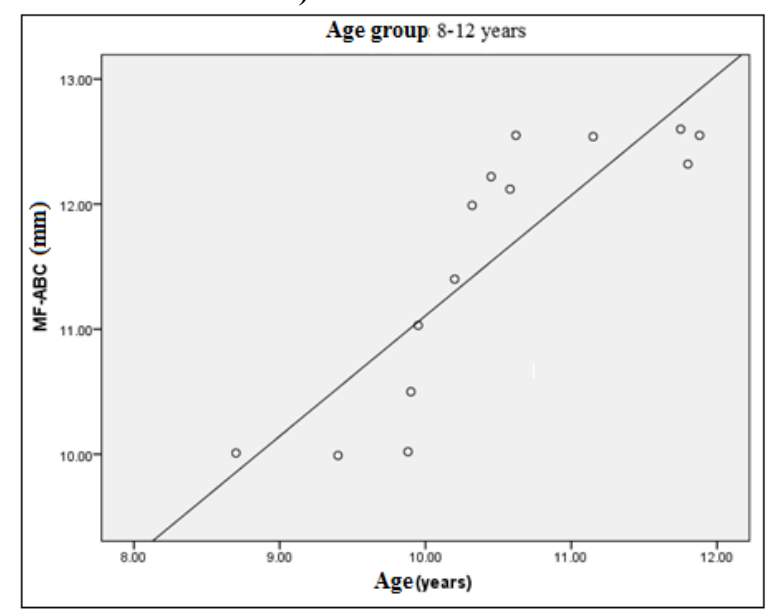

Figure (9): Scatter diagram showing correlation between chronological age and mental foramenmidline (MF-ABC) measurement in in the age group (8-12) of male cases.

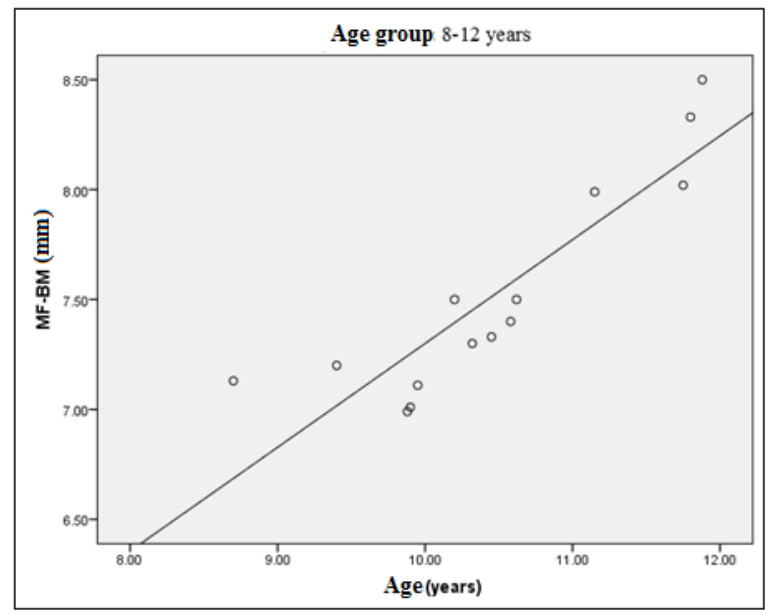

Figure (11): Scatter diagram showing correlation between chronological age and mental foramenmidline (MF-BM) measurement in in the age group (812) of male cases. 


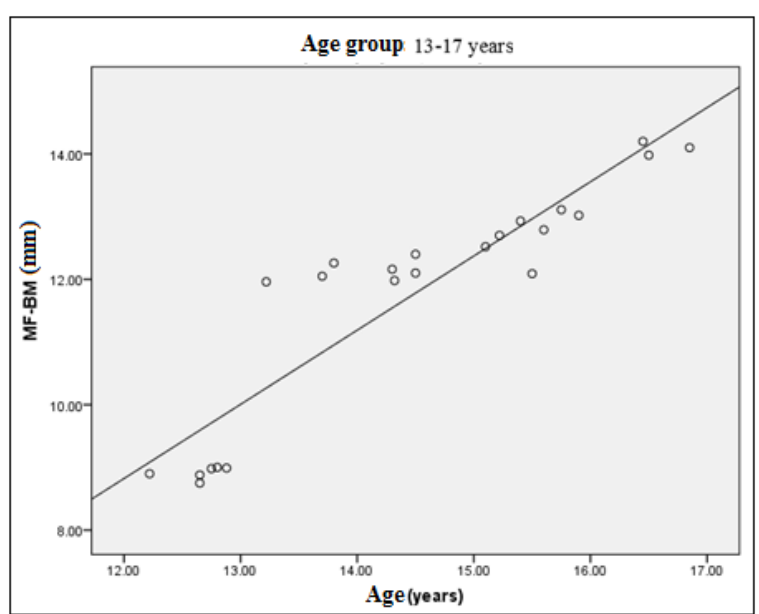

Figure (12): Scatter diagram showing correlation between chronological age and mental foramen- midline (MF-BM) measurement in in the age group (13-17) of male cases.

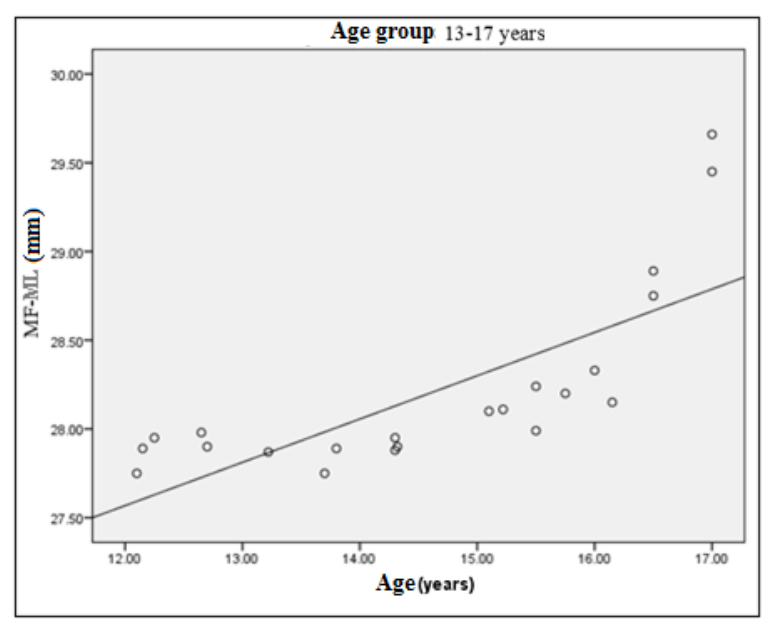

Figure (14): Scatter diagram showing correlation between chronological age and mental foramenmidline (MF-ML) measurement in in the age group (13-17) of female cases.

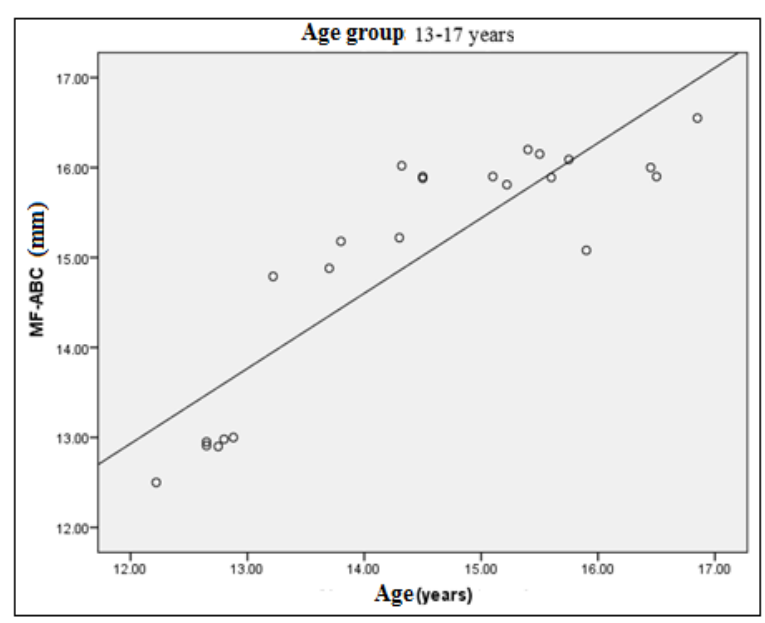

Figure (16): Scatter diagram showing correlation between chronological age and mental foramenmidline (MF-ABC) measurement in in the age group (13-17) of female cases.

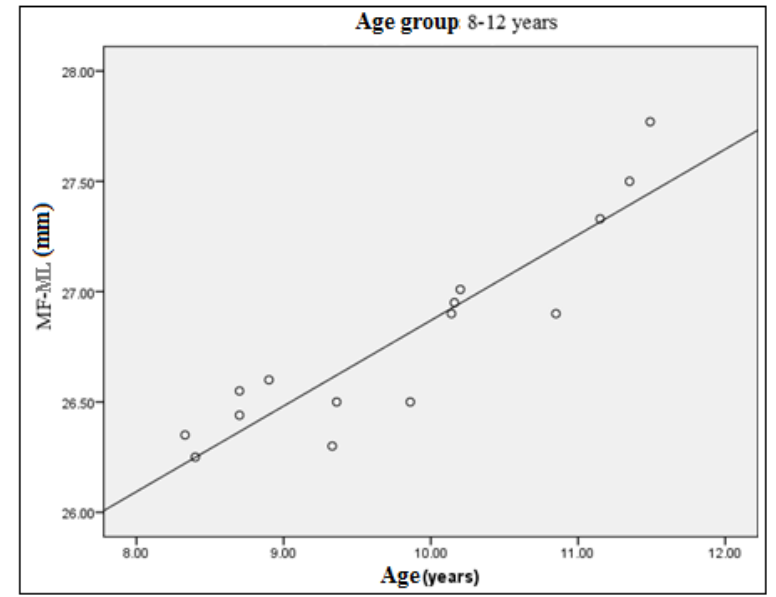

Figure (13): Scatter diagram showing correlation between chronological age and mental foramenmidline (MF-ML) measurement in in the age group (812) of female cases.

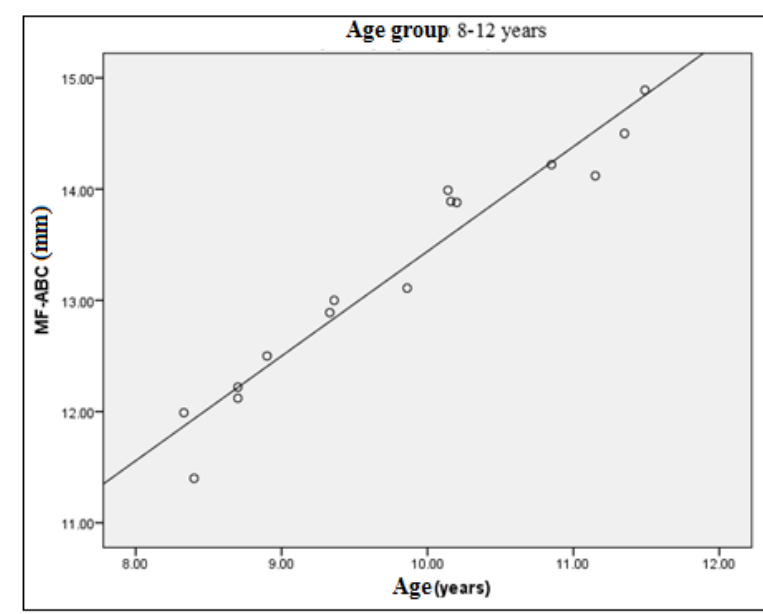

Figure (15): Scatter diagram showing correlation between chronological age and mental foramenmidline (MF-ABC) measurement in in the age group (8-12) of female cases.

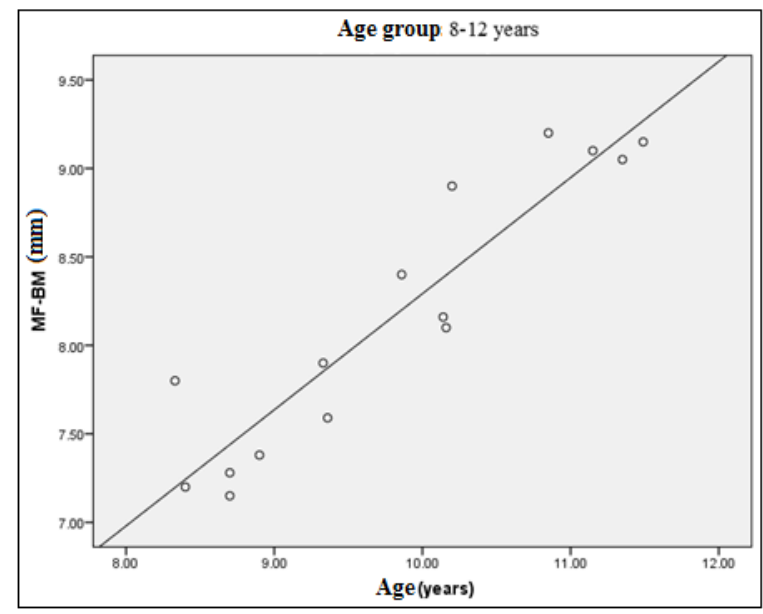

Figure (17): Scatter diagram showing correlation between chronological age and mental foramenmidline (MF-BM) measurement in in the age group (812) of female cases. 


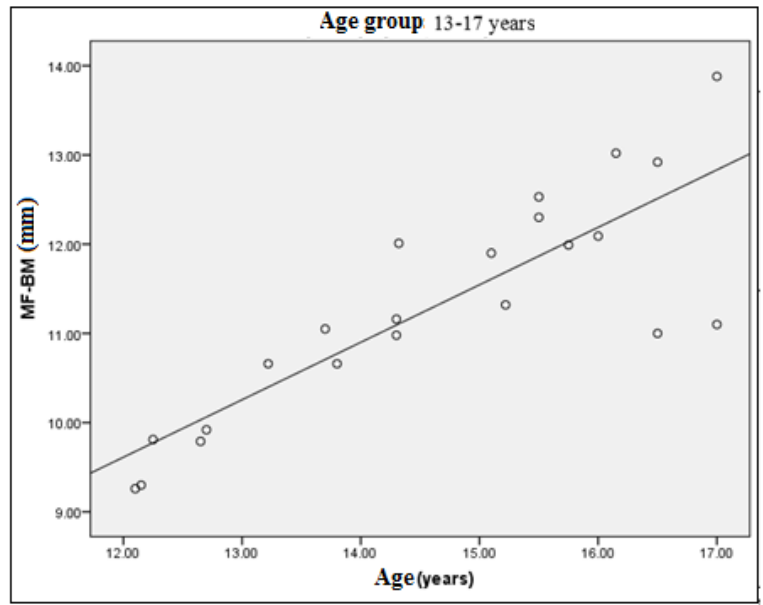

Figure (18): Scatter diagram showing correlation between chronological age and mental foramen- midline (MF-BM) measurement in in the age group (13-17) of female cases.

\section{Discussion:}

The mental foramen has been reported to vary in position in different ethnic groups and gender. It varies in position according to the age and sex as substantiated in several previous studies (Närhi et al., 1997; Dotto et al., 2006 and Juodzbalys et al., 2010).

The aim of this study was to determine the radiographic position of mental foramen in relation to anatomical structures in different age groups in some male and female Egyptians.

The age groups were determined according to different stages of growth and development as prepubertal (8-12 years), pubertal (13-17 years), adolescent (19-30 years), middle aged (31-50 years) and elderly people (51-70 years).

Panoramic radiographs were used in this study as they give much better view. Panoramic radiographs have advantages like bilateral visualization of anatomical structures, broader visualization of hard tissue areas, and the ability to visualize adjacent areas, thus allowing for a more standardized localization of mental foramen. Mental foramen position may not be revealed in a periapical radiographic film, if the position of mental foramen falls below the edge of the film. Comparative analysis between right and left foramen is also difficult on other conventional radiographs. It is because of this reason panoramic radiographs were selected to study mental foramen (Rupesh et al., 2011).

In this study, digital panoramic radiography was used, previous studies comparing digital panoramic images and conventional panoramic images showed that the measurement errors was less in the former (Peker et al., 2009).

In the present study, as regards horizontal position of mental foramen presented by the distance between mental foramen and midline (MF-ML), cases aged (8-12) years showed the statistical significant lowest mean values, followed by cases aged (13-17) years in both males and females. There was nostatistical significant difference between cases aged (18$30),(31-50)$ and (51-70) years; all showed the statistical significant highest mean values, their values were nearly equal. These results indicate that the distance between mental foramen and the midline increases in a significant accelerating manner in children and then becomes stable after the age of 18 .

On considering horizontal position of mental foramen presented by the distance from the mental foramen to the alveolar bone crest (MF-ABC) and the base of mandible (MF-BM), cases aged (8-12) years showed the statistical significant lowest mean values, followed by cases aged (13-17) years in both males and females. There was no-statistical significant difference between cases aged (18-30), (31-50) and (51-70) years.

The mean values of the distance between mental foramen and the base of mandible (MF-BM) were nearly equal in the later three age groups, while the distance from the mental foramen to the alveolar bone crest $(\mathrm{MF}-\mathrm{ABC})$ were nearly equal in the cases aged (18-30), (31-50), but in age group (51-70) the mean value decreased. These results indicate that the distance from the mental foramen to the alveolar bone crest and the base of mandible increases in a significant accelerating manner in children, becomes stable after the age of 18 and after the age of 50 the mental foramen becomes closer to the alveolar crest. This may be due to bone resorption as age advances (Peker et al., 2009).

It was observed that the first (8-12) and fifth (51-70) groups showed a reduced mean distance of mental foramen position from the alveolar bone crest when compared to second, third, and fourth groups.

In a study conducted by Gershenson et al. in 1986, he found that in children before tooth eruption, the mental foramen is somewhat closer to the alveolar margin; during the eruption period, the mental foramen descends to half way between the margins and in adults with the teeth preserved, the mental foramen is somewhat closer to the inferior border. With loss of teeth, the mental foramen moves upward closer to the alveolar border.

In general, these findings are in accordance with Mohamed et al. (2016) who studied the position of mental foramen in a sample of India population. They found that the distance between the mental foramen and 
each of the midline, the alveolar margin and the base of mandible increases with age advances during childhood and then becomes relatively stable during adulthood. In the elderly group, the mean distance of mental foramen position from the alveolar bone crest showed the least value when compared to other groups.

In the present study as regards sex difference, males showed higher mean values than females in all measurements in all age groups except in the age group (8-12) years.

The variation in position of the mental foramen between females and males in the first group (8- 12) may be attributed to the hormonal changes induced in growth spurts. In 1927, Hellman identified the pubertal growth spurt which is a marked adolescent acceleration in the rate of growth. This spurt in the peak of incremental growth has been found to occur approximately 2 years earlier in females than males, at mean ages of 12 years and 14 years, respectively (Gray et al., 1995).

The study by Ochoa and Nanda, 2004 showed that the female subjects tended to have the greatest skeletal changes between 10 years and 14 years of age, while the male patients had the greatest changes between 12 years and 16 years of age and even up to 18 years of age.

In the other age groups (13-17), (18-30), (3150) and (51-70), male patients showed a statistical significant increase in the mean distance of mental foramen position from the midline, alveolar crest and base of mandible. This change in the mean distance of mental foramen position could be due to the growth spurt favoring males after the age of 12 and lag of growth spurt in females. The female patients demonstrated a relative slowdown of growth after 14 years of age in mandibular length, whereas in the male patients jaws continued to grow significantly until 16 years of age (Gray et al., 1995). Furthermore, the muscular tension is considered an inductive factor of bone formation, and in the mandible, the contraction of the elevating muscles during masticatory movements exerts tension throughout the mandibular ramus. In general, men have stronger masticatory muscles than the women (Agthong et al., 2005).

In general, these findings are in accordance with related previous studies in other populations. Rashid and Ali (2011) examined a total of 300 Iraqi subjects, (150 male and 150 female), age distribution of them was ranging between (20-49) years old, linear vertical measurements were performed on the radiographic images related to the vertical position of the mental foramen, the mean values were higher in males than females and there was a high statistical significant difference between genders.

Thakur et al. (2014) signified the use of average measurements from the superior and the inferior borders of the mental foramen to the lower border of the mandible and to the alveolar crest on digital panoramic radiographs on right side in determining the gender in a sample from Pradesh, India. The results of the study showed statistically significant difference in males and females, so these measurements can be used to determine the gender.

Sahni et al. (2015) tested gender determination using mental foramen as landmark on panoramic radiographs in selected North Gujarat population, sixty persons were selected. Digital caliper was used to measure the distance from superior border of mental foramen to lower border of mandible (S-L) and inferior border of mental foramen to the lower border of mandible (I-L). The analyzed data of study showed that the mean values were significantly higher in males as compared to females. The results concluded a definite sexual dimorphism in the position of the mental foramen from the base of the mandible.

Ghouse et al. (2016) studded 60 Indian patients from Bengaluru, 30 males, and 30 females; age distribution was ranging between 20 and 49 years. The vertical position of the mental foramen was evaluated; the means of overall values were significantly higher in males in comparison to females in all age groups.

Singal and Sharma (2016) recorded the vertical measurements of mental foramen and correlated them to assess the sensitivity of these parameters in gender determination. Panoramic radiographs of a 100 Haryana individuals in India, including 50 males and 50 females were assessed. Statistical significant differences were observed between genders where males almost have higher measurements than females. This study concluded that the distances from the superior border of alveolar ridge to the superior margin of mental foramen of the mandible exhibit sexual dimorphism in this population.

In the present study on considering the results of Pearson's correlation coefficient, in the age groups (8-12 and 13-17), there was a statistical significant positive correlation between chronological age and the mental foramen position measurements, so regression analysis was developed in order to determine the equations for age estimation using these measurements.

Also the confidence interval test was used to obtain range for gender determination using the mental foramen position measurements. The values of $95 \%$ confidence interval of the distance from mental foramen to the midline (MF-ML) were (30.54-31.73) in males and (29.89-30.85) in females, the values of the distance from mental foramen to the alveolar bone crest (MF$\mathrm{ABC})$ were (15.26-16.23) in males and (14.57-15.37) in females, and the values of the distance from mental foramen to the base of mandible (MF-BM) were (12.4313.51) in males and (11.69-12.55) in females.

These results suggest that if the MF-ML is > $31.73 \mathrm{~mm}$, MF-ABC is $>16.23 \mathrm{~mm}$ and MF-BM > $13.51 \mathrm{~mm}$ on $\mathrm{OPG}$, the individual is likely to be male in $95 \%$ cases. If the MF-ML is $<29.89 \mathrm{~mm}, \mathrm{MF}-\mathrm{ABC}$ is $<12.43 \mathrm{~mm}$ and MF-BM is $<11.69 \mathrm{~mm}$, the individual is likely to be female in $95 \%$ cases.

\section{Conclusion}

The results of this study indicate that the mental foramen position of some Egyptians is not constant and changes as age advances. Also there is a gender related variation in the position of mental foramen in each age group studied. Using mental foramen position 
measurements it is possible to predict age and gender in panoramic radiographs.

\section{Recommendation}

Further research and studies are needed with extensive and large number of samples from different districts of Egypt, in order to accurate assessment of position of mental foramen in Egyptians that would help in establishing its role in forensic applications.

\section{References}

Agthong S, Huanmanop T and Chentanez V (2005): Anatomical variations of the supraorbital, infraorbital, and mental foramina related to gender and side. J. Oral Maxillofac. Surg.; 63(6):800-804.

Bou Serhal C, Jacobs R, Flygare L et al., (2002): Perioperative validation of localisation of the mental foramen. Dentomaxillofac. Radiol.; 31:39-43.

Bourke G, Daly LE and McGilvary J (1985): Interpretation and Uses of Medical Statistics (3rd ed.), London, Blackwell Scientific Publications. pp.10-105.

Chandra A, Singh A, Badni M et al., (2013): Determination of sex by radiographic analysis of mental foramen in North Indian population, J. forens. dent. Scien.; 5(1): 52-55.

Dotto SR, Travassos RM, Filho EM et al., (2006): Evaluation of the mental foramen position in pediatric patients. Cienc. Odontol. Bras.; 9: 14-20.

Durić M, Rakocević Z and Donić D (2005): The Reliability of sex determination of skeletons from forensic context in the Balkans. Forensic Sci. Int.; 147: 159-164.

Juodzbalys G, Wang HL and Sabalys G (2010): Anatomy of mandibular vital structures. Part II: Mandibular incisive canal, mental foramen and associated neurovascular bundles in relation with dental implantology. J. Oral Maxillofac. Res.; 1: 30-37.

Gershenson A, Nathan H and Luchansky E (1986): Mental foramen and mental nerve: Changes with age. Acta. Anat. (Basel); 126: 21-28.

Ghouse N, Nagaraj T, James L et al., (2016): Digital analysis of linear measurements related to the mental and mandibular foramina in sex determination. J. Med. Radiol. Pathol. Surg.; 2: 5-9.

Gray H, Williams PL and Bannister LH (1995): Gray’s Anatomy, The Anatomical Basis of Medicine and Surgery. 38th edition, New York, Churchill Livingstone, pp.164.

Haghanifar S and Rokouei M (2009): Radiographic evaluation of the mental foramen in a selected Iranian population, Ind. J. Dent. Res.; 20 (2): 249-253.

Hellman M (1927): Changes in the human face brought about by development. Int. J. Orthod. Oral Surg. Radiog.; 13: 475-516.

$\mathrm{Hu}$ KS, Koh KS, Han SH et al., (2006): Sex determination using nonmetric characteristics of the mandible in Koreans. J. Forens. Sci.; 51:1376-1382.

Jacobs R, Mraiwa N, Steenberghe D et al., (2004'): Appearance of the mandibular incisive canal on panoramic radiographs. Surg. Radiol. anatomy; 26(4): 329-333.

Junior OEM, Araujo ALD, Da Silva CMF et al., (2009): Morphological and morphometric study of the mental foramen on the MCP-18 jiachenjiang point. Int. J. Morphol.; 27(1): 231-238.

Komar D and Lathrop S (2006): Frequencies of morphological characteristics in two contemporary forensic collections: implications for identification. J. Forensic Sci.; 51(5): 974-978.

Malik M, Laller S, Saini SR et al., (2016): Mental foramen: An Indicator for Gender Determination - A Radiographic Study, Santosh University. J. Health Sci.; 2(1):12-14.

Matamala DAZ, Galdames ICS and Smith RL (2009): Sexual Dimorphism Determination from the Lineal Dimensions of Skulls. Int. J. Morphol.; 27(1): 133-137.

Mohamed A, Nataraj K, Mathew V et al., (2016): Mental foramen position using digital panoramic Radiographs. J. Forensic Dent. Scien.; 8: 79-82.

Närhi TO, Ettinger RL and Lam EW (1997): Radiographic finding: Ridge resorption, and subjective complaints of complete denture patients. Int. J. Prosthodont.; 10: 183-189.

Neves FS, Oliveira LS, Torres MG et al., (2010): Accessory mental foramen: Case report. RPG Rev. Post Gra.; 17: 173-176.

Ochoa BK and Nanda RS (2004): Comparison of maxillary and mandibular growth. Am. J. Orthod. Dentofacial. Orthop.; 125: 148-159.

Oguz O and Bozkir MG (2002): Evaluation of location of mandibular and mental foramina in dry, young, adult human male, dentulous mandibles. West Indian Med. J.; 51(1): 14-26.

Peker I, Gungor K, Semiz M et al., (2009): Localization of mental and mandibular foramens on the conventional and digital panoramic images. Coll. Antropol.; 33: 857-8162.

Pokhrel R and Bhatnagar R (2013): Position and number of mental foramen in dry human mandibles: Comparison with respect to sides and sexes. OA Anatomy; 1(4): 1-6.

Rashid SA and Ali J (2011): Sex determination using linear measurements related to the mental and mandibular foramina vertical positions on digital panoramic images. J. Bagh. College Dent.; 23: 59-64.

Rockenbach MI, Sampaio MC, Costa LJ et al., (2003): Evaluation of mandibular implant sites: correlation between panoramic and linear tomography. Braz. Dent. J.; 14: 209-213.

Rupesh S, Winnier JJ, John S et al., (2011): Radiographic study of the location of the mental foramen in a randomly selected Asian 
Indian population on digital panoramic radiographs. J. Med. Sci.; 11: 90-95.

Sahni P, Patel RJ, Jaydeva HM et al., (2015): Gender Determination by Pantomographic (OPG) Analysis of Mental Foramen in North Gujarat Population- A Retrospective Study. Med. Res. Chron.; 2 (5): 701-706

Shah PP, Parikh KK, Shah MJ et al., (2013): Radiographic Study of Mental Foramen in a Selected Indian Population in Kheda District, Gujarat. J. Indian Acad. Oral Med. Radiol.; 25(1): 13-17.

Shah S, Vaze S and Kinhal K (2010): A variation in the position of the mental foramen: A case report. J. Maxillofac. Oral Surg.; 9: 30-39.
Singal K and Sharma S (2016): Gender Determination by Mental Foramen Using Linear Measurements on Radiographs: A Study in Haryana Population. Indian J. Forensic Medic. Toxicol.; 10(1): 44-49.

Sweet D (2001): Why a dentist for identification. Dent. Clin. North Am.; 15: 237-2351.

Thakur M, Reddy KV, Sivaranjani Y et al., (2014): Gender Determination by Mental Foramen and Height of the Body of the Mandible in Dentulous Patients, A Radiographic Study. J. Indian Acad. Forens. Med.; 36(1): 13-18.

Wang, TM, Shih C, Liu JC et al., (1986): A clinical and anatomical study of the location of the mental foramen in adult Chinese mandibles. Acta. Anat.; 126(1): 29-33.

\section{الملخص العربي}

\section{دراسة الاختلافات المتعلقة بالسن والجنس في وضع الثقب الأقني لبعض المصريين باستخدام الأشعة البانوراميةً الرقمية الثبية}

\section{عفاف عبدالرؤوف شعبان 1 وأسامة سيد أحمد الثال2 2}

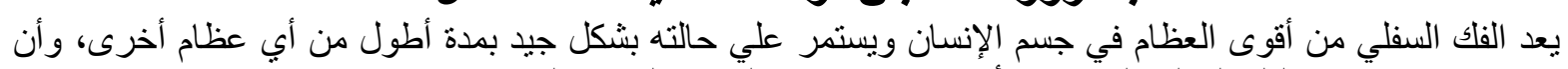

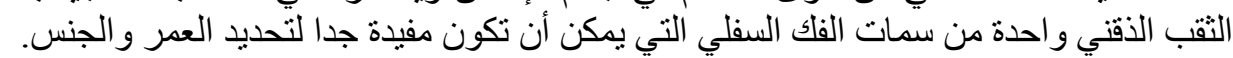

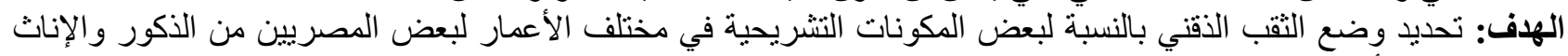

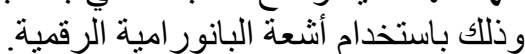

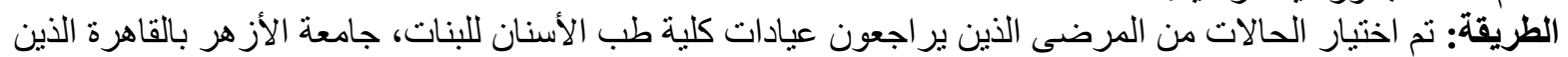

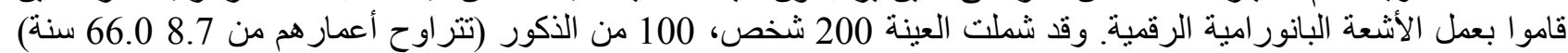

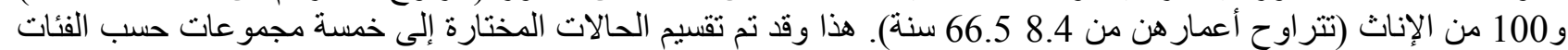

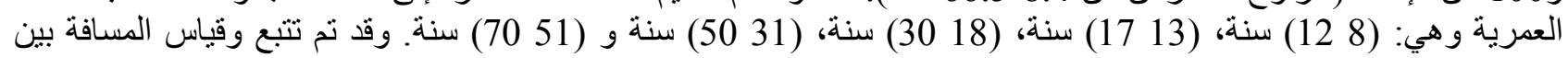

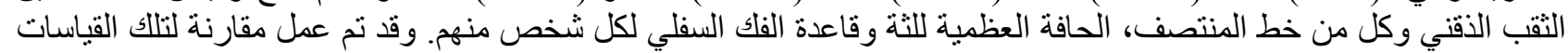

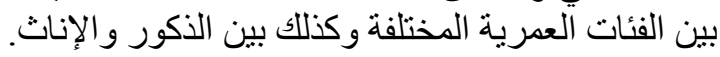

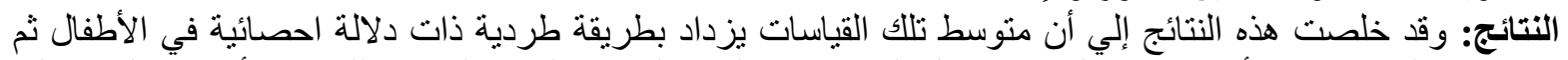

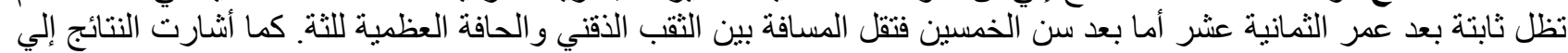

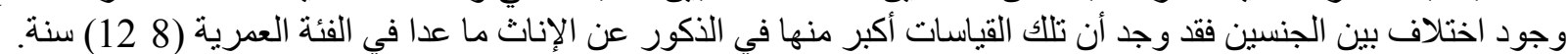

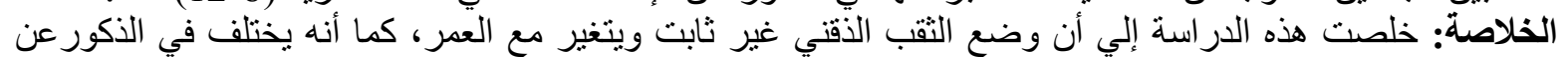

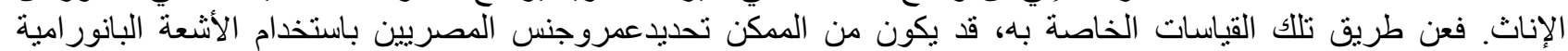

التوصيات: إجر اء المزيد من الدراسات والأبحاث علي عدد كبير من المصريين من مناطق مختلفة وذللك للتقييم الدقيق

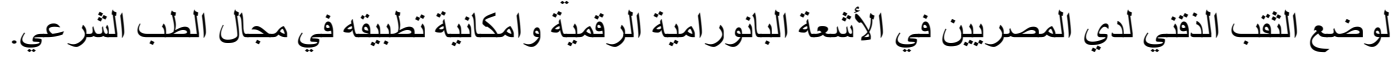

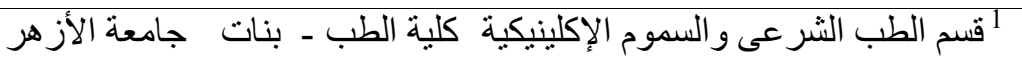

$$
\begin{aligned}
& \text { - القاهرة الطن } \\
& \text { قسم طب الفم والأشعة التشخيصية كلية طب أسنان - بنات جامعه الاز هر }
\end{aligned}
$$

